\title{
LIFETIME VALUE IN BUSINESS PROCESS
}

\author{
M. Souček, J. Turčínková
}

Received: December 17, 2010

\begin{abstract}
SOUČEK, M., TURČÍNKOVÁ, J.: Lifetime value in business process. Acta univ. agric. et silvic. Mendel. Brun., 2011, LIX, No. 2, pp. 291-298

The paper focuses on lifetime value assessment and its implementation and application in business processes. The lifetime value is closely connected to customer relationship management. The paper presents results of three consecutive researches devoted to issues of customer relationship management. The first two from 2008 and 2010 were conducted as quantitative ones; the one from 2009 had qualitative nature. The respondents were representatives of particular companies. The means for data collection was provided by ReLa system. We will focus on individual attributes of lifetime value of a customer, and relate them to approaches of authors mentioned in introduction. Based on the qualitative research data, the paper focuses on individual customer lifetime value parameters. These parameters include: the cost to the customer relationship acquisition and maintenance, profit generated from a particular customer, customer awareness value, the level of preparedness to adopt new products, the value of references and customer loyalty level. For each of these parameters, the paper provides specific recommendations. Moreover, it is possible to learn about the nature of these parameter assessments in the Czech environment.
\end{abstract}

lifetime value, customer, customer relationship management

The current trend in marketing is to increase use of customer relationship management tools. The assessment of lifetime value belongs to the fundamentals of these tools. Customer lifetime value (CLTV) becomes an important indicator for implementation of differentiated (customized) customer relationship management.

The customer lifetime value is one of the metrics used for assessment of benefits coming from keeping and maintaining a relationship with a customer. Often it is expressed as a net current value of revenue inflow generated by a particular customer in a given time period. This calculated value provides us with possibility to differentiate among customers and their contributions to our business. Companies should focus on customers with higher lifetime value in their customer relation management. At the same time, they should stimulte customers with lower lifetime value to leave this category, and, for example, increase the turnover of their orders (Ferrel, Hartlin, 2005).

A different approach to customer lifetime value provide Clow a Blaack (2004) who include in their lifetime value calculations also an average number of visit within one year, average costs per visit, and an average length of relationship with a particular customer. The value is reduced by costs necessary for building a relationship and its maintenance. The value should be increase by number of references that a customer provides to further potential customers. The final value should also reflect the total length of relationship with a particular customer.

Hoffman et al. (2005) note that CLTV is a value that should provide sufficient information about a customer and provide possibilities for estimates of his future purchases.

Hughes (2003) approaches to CLTV strictly on economic basis. According to him, the value should represent net profits that can be generated by a particular customer within the total length of the mutual relationship.

Kumar (2008) describes the principles of lifetime value assessment in his book Customer Lifetime Value. The process is presented in figure 1. 


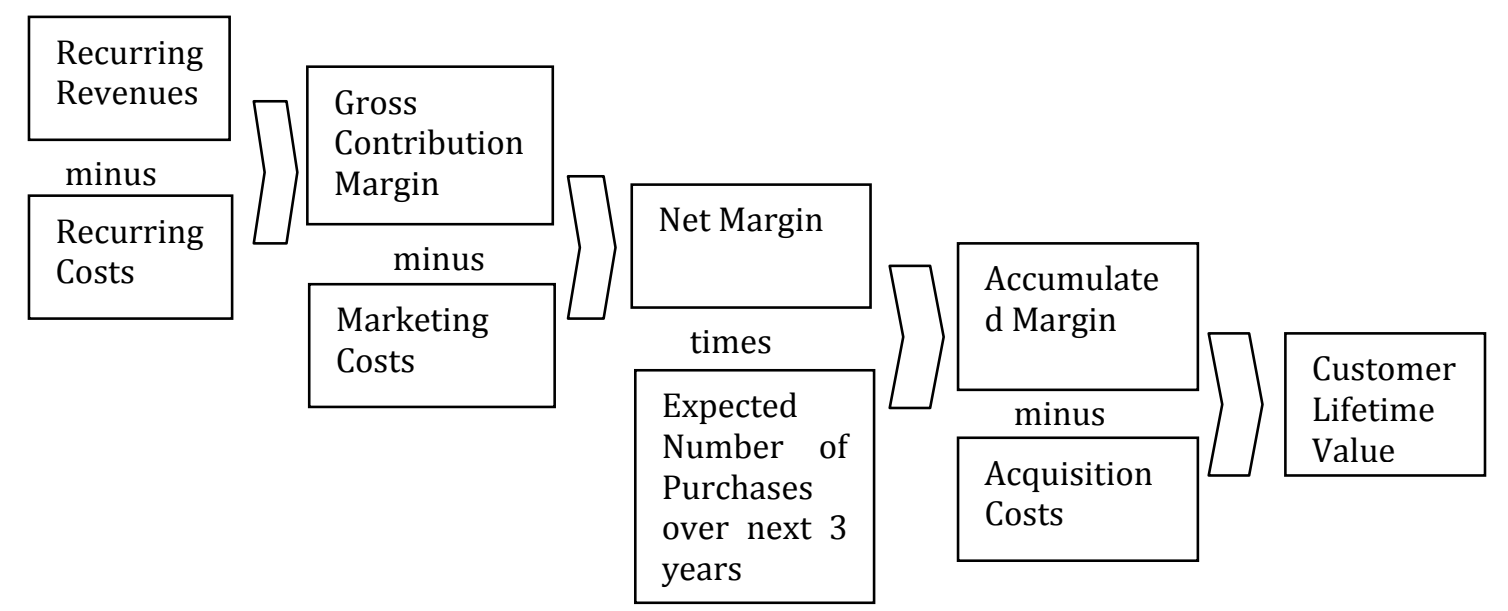

1: Approach to CLV measurement (Kumar, 2008)

\section{METHODS AND RESOURCES}

The data was collected via questionnaire survey. The first data collection was conducted in 2008, followed by data collection in 2010, using the same questionnaire. Data was collected via online questionnaire using a questionnaire survey system ReLa, developed by Department of Marketing and Trade at Faculty of Business and Economics at Mendel University in Brno. After data export from the database to MS Excel, the data was edited and incomplete or improperly filled out questionnaires were filtered out. For statistical analyses the Statistica 9.0 software was used.

All entries were process in frequency tables (Minařík, 2008):

- Absolute frequency:

$$
\sum_{i=1}^{k} n_{i}=n
$$

where $n_{i}$ represents the number of values in a category,

- Relative frequency:

$$
p_{i}=\frac{n_{i}}{n}
$$

where

$$
\sum_{i=1}^{k} p_{i}=1
$$

\section{Sample characteristics}

The structured questionnaire was completed by 2020 respondents (representatives of companies and institutions) in 2008 and by 831 respondents in 2010. The method of respondent selection was a random sampling. The required respondent identification was: company size, industry, turnover and region where company operates. Although the sample doesn't match parent population completely and we can't, therefore, consider it to be a represen- tative sample, we can say that this shortcoming can be compensated with the great sample size

Additional source was a qualitative research conducted in 2009 via face-to-face interviews with competent persons from companies of different industries, sizes and locations. Totally there were 141 interviews conducted. Choice of the parameters of cutomer lifetime value resulted from previous experiences and known models.

\section{RESULTS AND DISCUSSION}

At the beginning of each relationship, there always is a problem with lack of information about new (potential) customer. Therefore, it is necessary to evaluate the new customer from freely available secondary data, mainly national statistical data. In case of customers with whom company maintains relationships longer, there are several parameters we may use for customer assessment. The following results focus on such parameters.

\section{Cost of relationship with a customer}

The costs of customer relationship in terms of calculating the customer are very substantial figure. However, the major problem is the calculation for a particular customer. The calculation is extremely difficult and, according to many authors, it is impossible to achieve absolutely precise numbers, especially since it is not possible to calculate exact marketing costs.

This can be documented by an example of radio advertising, when we cannot calculate the average costs (typically calculated as cost per thousand - CPT) based on number of customers who were influenced by the spot or who have not even heard it. The very degree of influence is very difficult to specify, and if we would try to achieve it, then it is necessary to conduct a very detailed analysis.

Most company representatives indicated in our qualitative research that they quantify the total costs, but they cannot calculate accurately costs of a particular customer. The results of quantitative surveys 


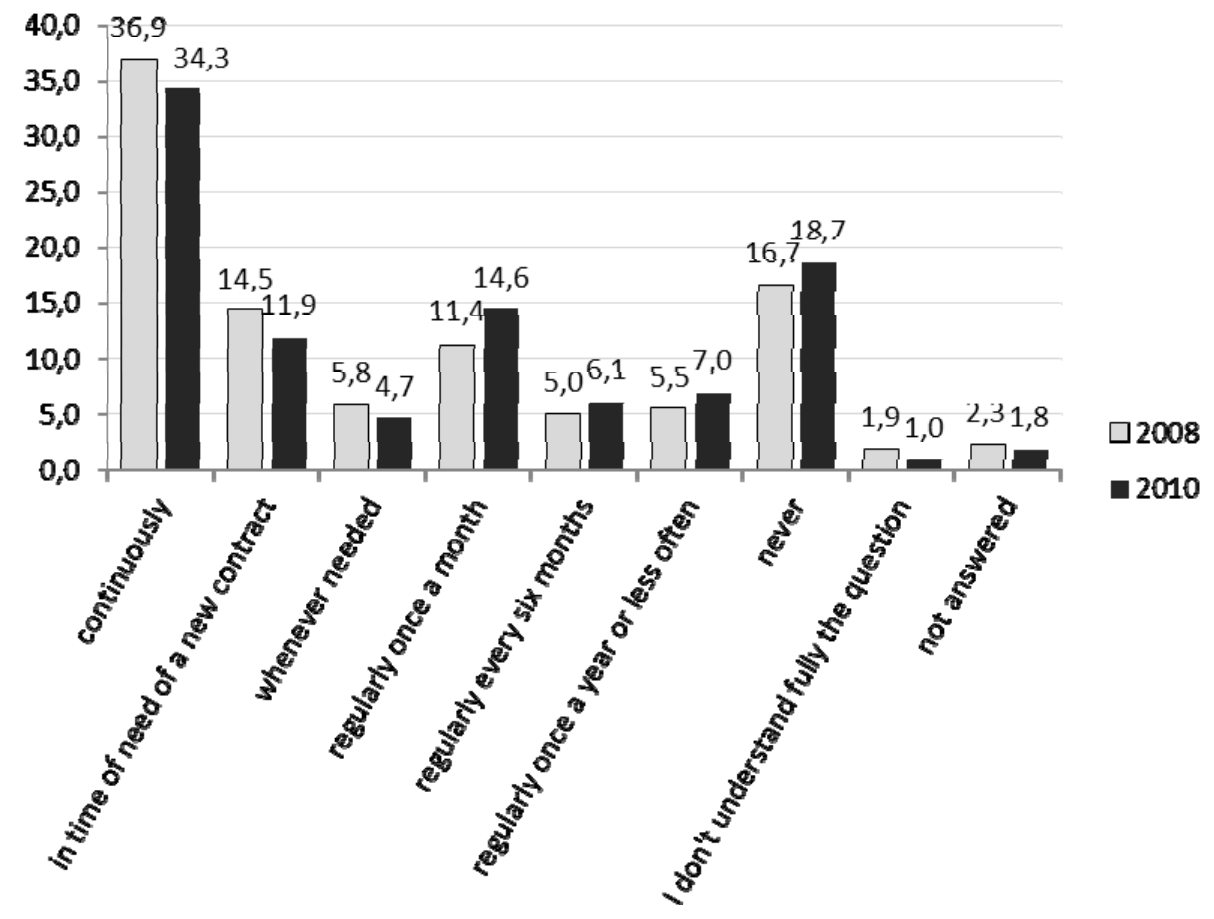

2: The cost of the customer relationship (2008 and 2010; in \%)

Source: Questionnaire surveys $2008(\mathrm{n}=2020)$ and $2010(\mathrm{n}=831)$

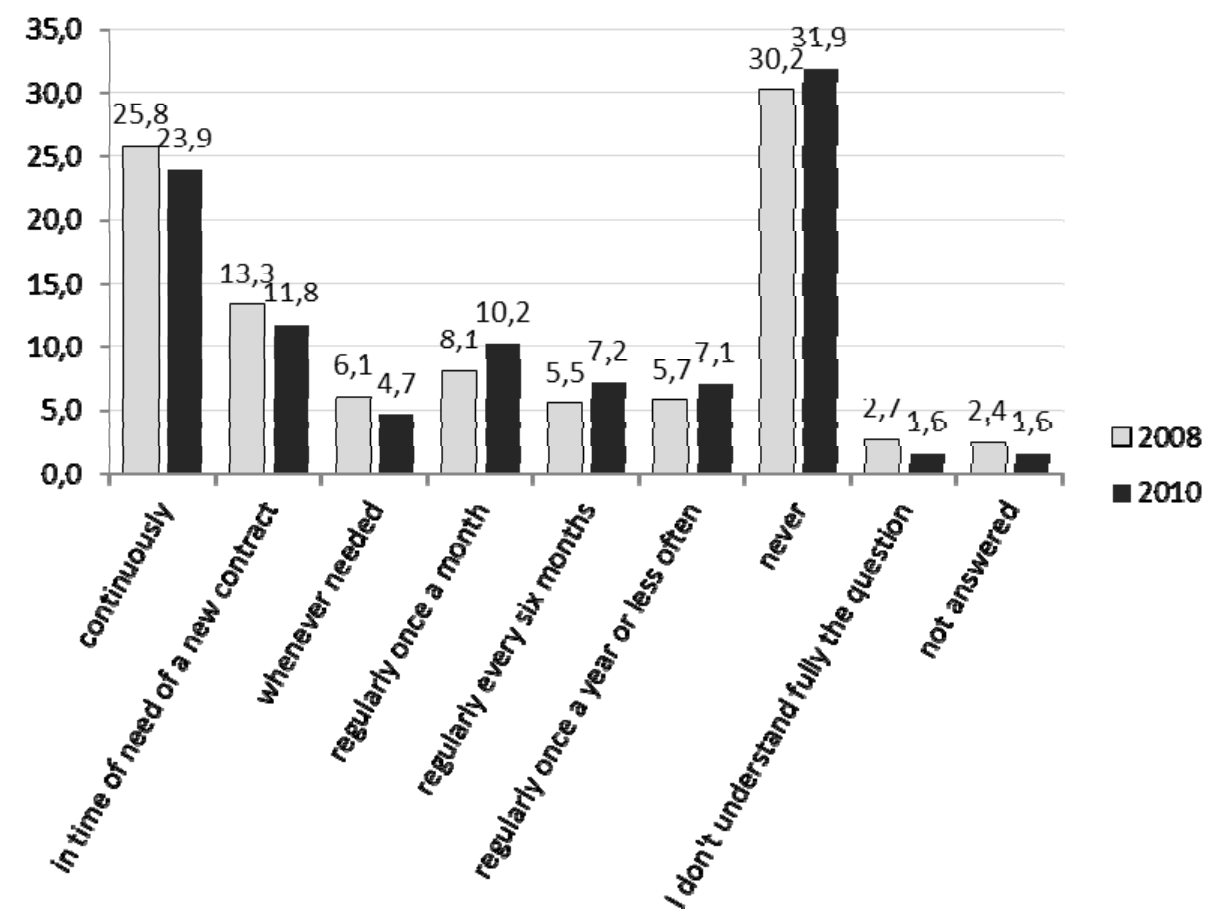

3: Marketing costs of a relationship (2008 and 2010; in \%)

Source: Questionnaire surveys $2008(n=2020)$ and $2010(n=831)$

in 2008 and 2010 show that costs of customer relationship are mostly followed on an ongoing basis. From the graph in Figure 2 it is obvious that there are no significant changes in prefered methods of following customer relationship costs in both analyzed years. 


\section{Marketing costs}

Marketing costs are generated by activities which are designed to promote products to customers. Their overall quantification is not too problematic. However, the calculation of costs distribution per individual customers in case of more complex promotion is almost impossible. As one respondend noted aptly: "Marketing costs are very specific, with a very unique structure for each customer that we can not quantify"

Some marketing communication tools are possible to quantify (e.g. gifts), but again the problem arises if the costs were also able to generate income so again, we may reconsider the earlier mentioned impact.

The vast majority of respondents indicated that they cannot quantificatify marketing costs per customer, only the total marketing costs. Very often companies deal with this problem simply by dividing the total costs by number of customers. The results listed in Figure 3 shows that respondents don't usually keep track of exact marketing costs per particual customer. The results didn't provide any significant shift in the research from 2010.

\section{Customer Loyalty}

Customer loyalty is one of the major indicators of company success. Most respondents mentioned that they assess loyalty on the basis of length of cooperation duration with a specific customer. It's a very simple method of calculation, however, it doesn't provide us with information, whether the customers do not also purchase from other companies. In
B2B markets, this value may reflect the reality, however, in the B2C market, the application is not very meaningful.

A somewhat better method of determining customer loyalty is a calculation based on the principle of count of orders during an analyzed period, if any, compared with historical data. As an indication of loyalty, it is also possible to evaluate the regularity of service checks on products purchased. In some cases, loyalty is evaluated by comparing the company with direct competitors offering substitute products. An alternative is also a benchmarking method of affiliates of one company with one another.

Customer loyalty should be evaluated at regular (monthly) intervals and if there are fluctuations, there might be a need for personal meetings with customers. Very often, the loyalty is evaluated on the basis of individual and subjective assessments by sales representatives.

Many companies try to deal with customer loyalty through a preliminary inquiry on what would make them leave and purchase from competition. The company then tries to avoid this. Companies generally maintain the customer loyalty through discount policies and monitor customer response to a specific event discount. Results of our studies show that this parameter is monitored by firms in both report periods regularly (Figure 4).

\section{Customer awareness}

This parameter of customer lifetime value is used by the companies the least often. Most companies

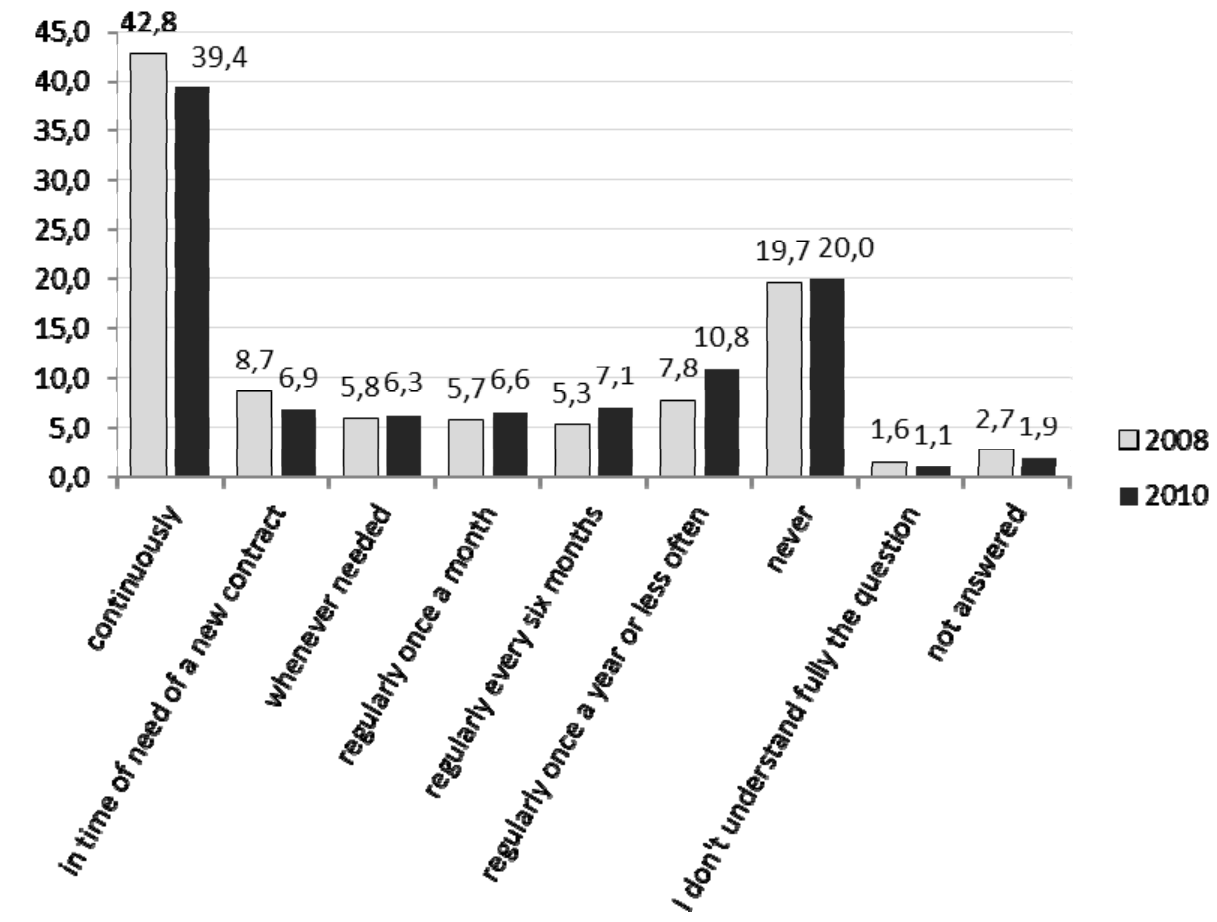

4: Value of customer loyalty (2008 and 2010; in \%)

Source: Questionnaire surveys $2008(\mathrm{n}=2020)$ and $2010(\mathrm{n}=831)$ 


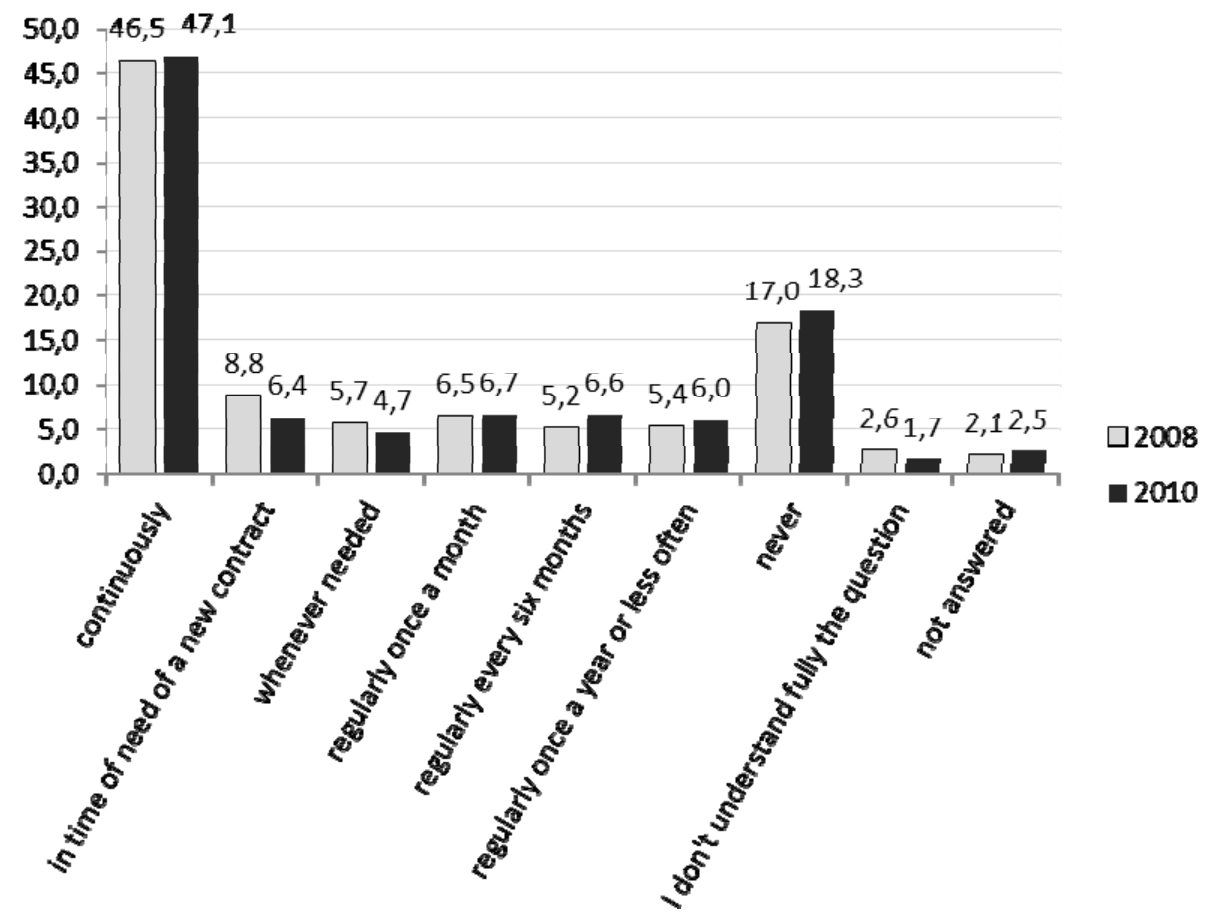

5: Value of customer awareness (2008 and 2010; in \%)

Source: Questionnaire surveys $2008(\mathrm{n}=2020)$ and $2010(\mathrm{n}=831)$

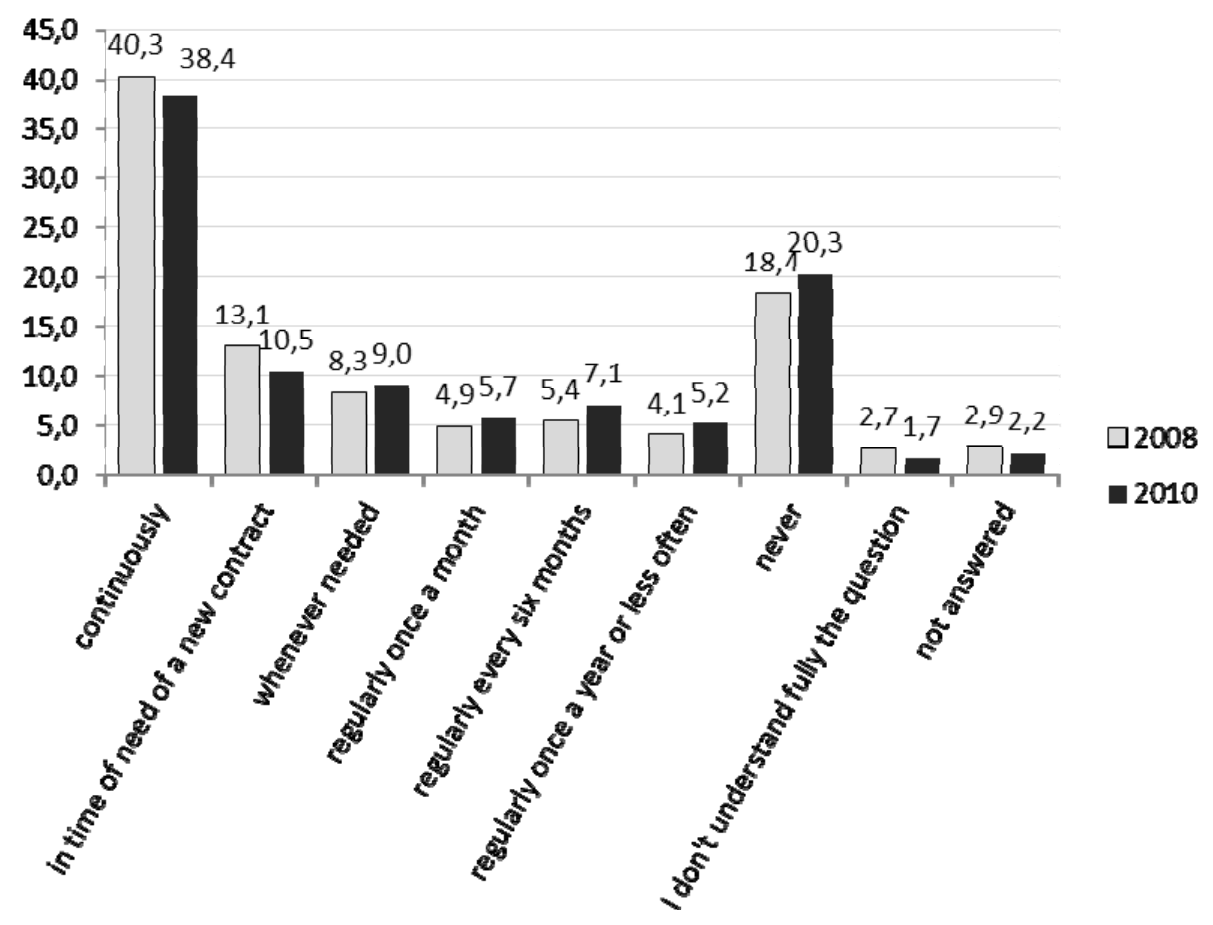

6: Value of the ability to accept new products (in \%)

Source: Questionnaire surveys $2008(\mathrm{n}=2020)$ and $2010(\mathrm{n}=831)$

normally try to regularly inform their customers throught multiple channels. Most of the feedback and verification of information is provided through company sales representatives or through direct mail or telephone contact. In either case, there was no evaluation of this information as input for customer value.

Less frequently is the customer awareness evaluated by linking web pages to customer accounts. As a key indicator of customer awareness is reported 


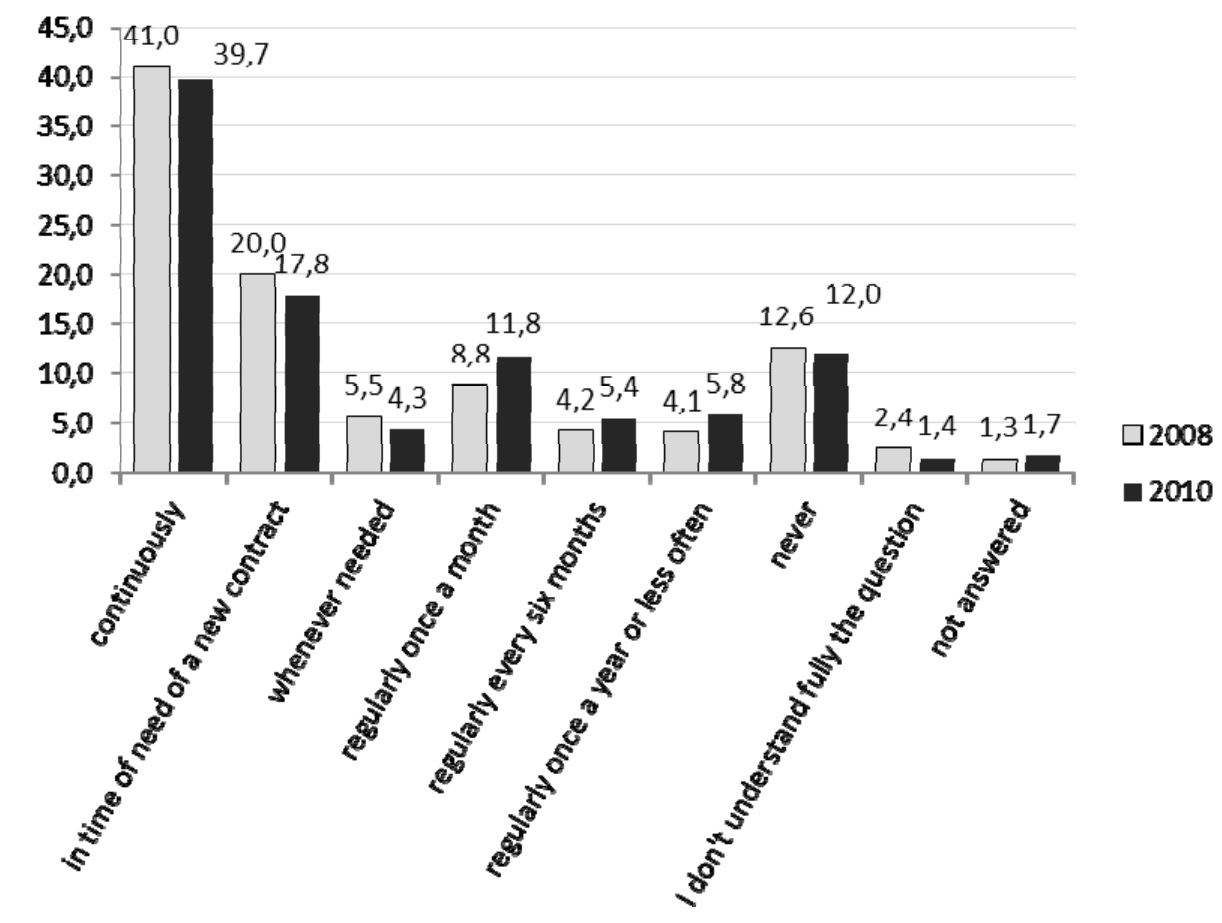

7: Value of profit from the relationship to the customer (in \%)

Source: Questionnaire surveys $2008(\mathrm{n}=2020)$ and $2010(\mathrm{n}=831)$

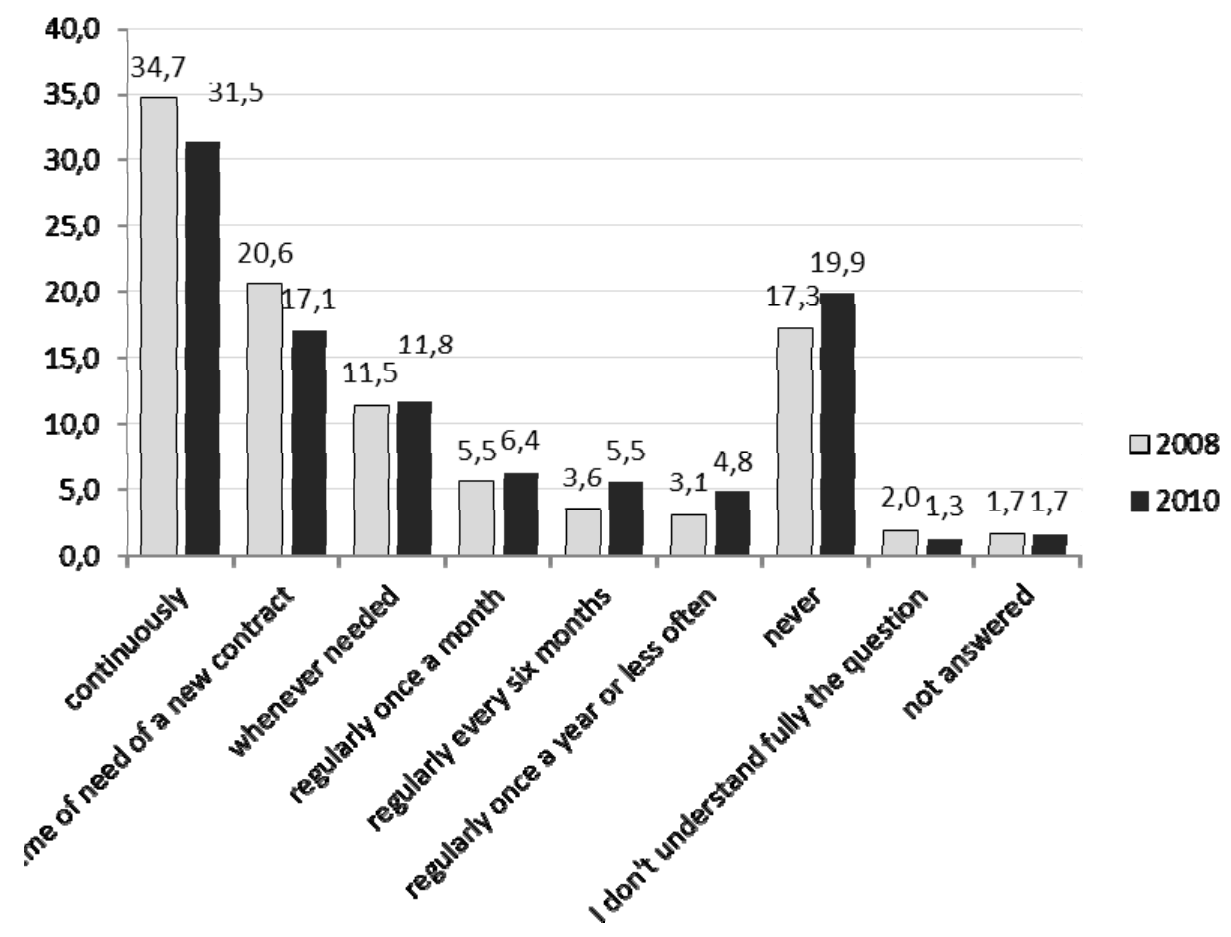

8: Reference value (2008 and 2010; in \%)

Source: Questionnaire surveys $2008(\mathrm{n}=2020)$ and $2010(\mathrm{n}=831) x x$

a reactions in the form of contract, however, without verification of the information availability. An alternative is also the relationship between customer awareness and total sales, however, this indi- cator does not allow the the assessment of customer awareness of a particular client.

One possibility, which is also used by companies, is customer data collection via questionnaire sur- 
veys. In several cases, companies undertake research of a qualitative nature, most frequently in a form of focus groups. From the quantitative research (results in Figure 5) we can tell this information about customer awareness is collected on regualar basis, but they do not indicate inclusion of this parameter to the customer lifetime value calculation.

A similar parameter as the value of customer awareness that can be detected and assessed in customer relationship management is also the level of new product adoption. The results in figure 6 show again the trend to detect these data by companies continuously.

\section{Customer relationship profitability value}

In fact, it is one of the most essential parameters of customer lifetime value calculation. Many principles of CLTV calculation were mentioned in the introduction in this paper. From the figure 7, it is evident that distribution of answer is different than in previously discussed items. In particular, there was a decrease in frequency of answers "never". Only $12 \%$ of firms don't track the value of earnings from a particular relationship with the customer in both analyzed years.

\section{Customer recommendations (word-of-mouth)}

Positive word-of-mouth could be considered as the best kind of promotion, which doesn't bring any direct costs. For a firm are more valuable those customers, who spread their positive word-of-mouth the most. It is very difficult, however, to assess the value of word-of-mouth and in most cases are the assessments are resolved through various polls and surveys (including telephone and electronic). Often, the firms interview their new customers - where did they receive information that caused them to buy and such.

In an IT environment, we can see a visible growth of afilate benefit programs use, through which it can be very accurately determined, what customer has recommended a purchase to a new customer. This system is not new, nevertheless, in this environment it allows to achieve very accurate results. The survey (Figure 8) again did not reveal any significant shifts between results from 2010 and 2008.

The results indicate that none of the attributes can be calculated exactly. However, it is necessary to realize that the quantification of customer lifetime value is not expected to be an accurate number that defines the individual customer or group segment. The essence of customer lifetime value is the division of customers into several groups to which we target and service individually. Consequently, it is possible to use all above mentioned attributes. However, it is recommended to adjust the calculation to a particular sector.

\section{SUMMARY}

The paper deals with issues of customer lifetime value. The introduction elaborates several approaches to determine customer lifetime value and discusses the attributes in the results. The results are based on three studies. Two surveys carried out between 2008 and 2010 to acquire the quantitative data via questionnaires. The third research was carried out in 2009 via face-to-face interviews in order to obtain qualitative data.

Based on the qualitative research data, the paper focuses on individual customer lifetime value parameters. These parameters include: the cost to the customer relationship acquisition and maintenance, profit generated from a particular customer, customer awareness value, the level of preparedness to adopt new products, the value of references and customer loyalty level. For each of these parameters, the paper provides specific recommendations. Moreover, it is possible to learn about the nature of these parameter assessments in the Czech environment.

Two studies using the same questionnaire were conducted in 2008 ( $\mathrm{n}=2020)$ and in $2010(\mathrm{n}=831)$. The respondents were representatives of particulare companies. The means for data collection was provided by ReLa system. Results are always displayed for two years in a graph, we can observe no significant shift in monitored parameters.

The results show that the cost of customer relationship is mostly evaluated continuously, in 2008 it was $37 \%$ of companies, in $201034 \%$ companies. A large proportion of respondents (19\%) of this value does not assess these costs at all.

Marketing costs of a relationship are not monitored by 30\% of firms. In 2008, 25\% companies kept a record of these costs continuously, in 2010 it was $23 \%$ of them.

Value of customer loyalty was evaluated by $42 \%$ of respondents (in 2008), and 39\% (in 2010) continuously. Similar results were collected for indicator "value of customer awereness". Again, it was assessed continously in $46 \%$ of companies (in 2008) and by $47 \%$ of companies in the second data collection.

Value of the ability to accept new products was evaluated by $40 \%$ in 2008 and 38\% in 2010, while value of profit from the relationship to the customer, a very important indicator, was collected regularly by $41 \%$ (2008), and $40 \%$ companies in 2010. Reference value was also measured continuously by on third of companie (35\% in 2008, $32 \%$ in 2010). 


\section{Acknowledgements}

This paper was created in support of faculty research plan id. code: 6215648904 "The Czech economy is in the process of integration and globalization and development of the agrarian sector and service sector in the new conditions of European integrated market", thematic area of 03 "Development of relations in business sector in relation to changes in lifestyle and purchasing behavior of the population and changes of business environment in processes of integration and globalization" implemented with financial support from state funds through the Ministry of Education.

\section{REFERENCES}

FERREL, O. C., HARTLINE, M. D., 2005: Marketing Strategy. USA: South-Western, Part of the Thomson Corporation, 628p. ISBN: 0-324-23381-7, Package ISBN: 0-324-20140-0.

CLOW, K. E., BAACK, D., 2004: Integrated Advertising, Promotion, and Marketing Communications. New Jersey: Pearson Prentice Hall, 538 p. ISBN: 0-13-140546-2.

HOFFMAN, D. K., CZINKOTA, M. R., DICKSON, P. R., DUNNE, P., GRIFFIN, A., HUTT, M. D., KRISHNAN, B. C., LUSH, R. F., RONKAINEN, I. A., ROSENBLOOM, B., SHETH, J. N., SHIMP, T. A., SIGUAW, J. A., SIMPSON, P. M., SPEH, T. W.,
URBANY, J., 2005: Marketing Principles and Best Practises. USA: South-Western, Part of the Thomson Corporation, 598 p. ISBN: 0-324-22135-5, Package ISBN: 0-324-20044-7.

HUGHES, M., 2003: The customer loyalty sulution: what works (and dosesn't) in customer loyalty programs. New York: Professional publishing. 364 p. ISBN: 0-07-136366-1.

MINAŘÍK, B., 2008: Statistika I. Brno: Mendelova zemědělská a lesnická univerzita v Brně, 105 s. ISBN 978-80-7375-152-4.

KUMAR, V., 2008: Customer lifetime value: the path to profitability. Boston: now, 99 s. Foundations and trends in marketing. ISBN 9781601981561.

Address

Ing. Martin Souček, Ing. Jana Turčínková, Ph.D., Ústav marketing a obchodu, Mendelova univerzita v Brně, Zemědělská 1, 61300 Brno, Česká republika, e-mail: martin.soucek@mendelu.cz, jana.turcinkova@mendelu.cz 